\title{
Emerging Themes of the Leadership and Green Innovation of the Government-Linked Companies
}

\author{
Noormaizatul Akmar Ishak ${ }^{1}$ and Hartini Ahmad ${ }^{2}$ \\ ${ }^{1}$ Centre of Communication Skills and Entrepreneurship, Universiti Malaysia Kangar, Perlis, Malaysia \\ ${ }^{2}$ College of Business, Universiti Utara Malaysia, UUM Sintok, Malaysia
}

\begin{abstract}
The main reason businesses need to innovate is due to its necessity to sustain and survive, and not for the matter of how brilliant and visionary the leaders of the organisation are. Innovation has known for its very significant role in the organisation progression and growth. Innovation can happen in the products, processes, and services being embarked by organisations to make more profit by reducing operational cost and making processes more efficient. The concern over the environment all around the world has encouraged innovation to be more tailored to the "green". "Green" is a name that is being associated with anything or any action that has impact to the environment such as green building, green government and green innovation. This constructive research is a qualitative multicases study. Data collection is done via interviews, focus group discussions and document analysis. The result has been analyzed to see the themes emerging from the data before the analysis is being interpreted. This paper discusses the impact of green innovation to the top management leadership in the Government-linked Companies (GLCs) in Malaysia. The key findings highlighted that the leadership must be sensitive and must understand the green demand and situation in Malaysia and around the world with respect to the industries that these GLCs are operating. This is where the top management leadership "attribute" is justified to fit the green innovation implementation.
\end{abstract}

Keywords: green innovation, sustainability, top management leadership, government-linked companies

\section{Introduction}

\section{Background of the Study}

2010 Malaysia Green Forum held in Putrajaya on 26 April 2010 had seen a lot of incentives that would be given by the government to promote a better environment. The Prime Minister announced that the government is considering tax deductions for contributions toward environment funds and for designing buildings that work harmoniously with nature which would be revealed during the 2011 budget. These incentives such as the green technology soft loan scheme with funds amounting to RM1.5 billion are meant to encourage the exploration of green technology and practices. Indirectly, the "green collar" jobs will help in developing

Copyright (C) 2011 Noormaizatul Akmar Ishak and Hartini Ahmad. This is an open access article distributed under the Creative Commons Attribution License unported 3.0, which permits unrestricted use, distribution, and reproduction in any medium, provided that original work is properly cited. Contact author: Noormaizatul Akmar Ishak e-maill: maizatul@unimap.edu.my 
local green technology and spur the transformation of the country into a green economy (Karim, 2010). In Malaysia, the effort has been hugely supported by the government and its agencies including the Government-linked Companies (GLCs). The promotions about the Earth Hour have been advertised massively in the multimedia for weeks. Petroliam Nasional Berhad (PETRONAS) as one of biggest GLCs in Malaysia whose business success is believed to depend upon balancing the economic, social and environmental objectives as embodied in their Corporate Sustainability Framework. On the 27 March 2010, PETRONAS participated in switching off nonessential lights at its facilities for one hour, including the PETRONAS Twin Towers, the Suria KLCC shopping mall, petrol stations and its other premises around the world from $8.30 \mathrm{pm}$ to $9.30 \mathrm{pm}$ Malaysia time. PETRONAS made a long-term commitment in 2007 through its Energy Loss Management (ELM) framework that sets out medium and long-term targets for reducing energy consumption and improving energy efficiency, including reducing greenhouse gas emissions, across its operations (PETRONAS, 2010).

Since the late 1980s, environmentalist activist organisations have advocated the use of consumer pressure through boycotts of environmentally damaging products and through positive purchasing of green products, to influence what firms offer for sale, and, indeed, to influence their policies toward the environment overall (Green, Morton \& New, 2000).

From the above discussion on the motivation for green innovation, top management has to face and realise that green is the best solution for current issues in order for their business to be continually accepted by the consumer. Without the support from the consumers, companies cannot grow and sustain for a long time.

Green innovation as the focus of this study concentrates on the technological innovation in the 'green' or 'environmentally-friendly' context. Technological innovation is a part of the larger process of technological change, which consists of invention, innovation and diffusion. The difference between the three is that inventions are new technical ideas or devices, innovation is the first commercial or practical use of an invention and diffusion is the adoption of innovations by others. The government's role in invention is fairly straight forward: funding basic science and technology and protection of intellectual property rights. Although still not without difficulties, we currently have a greater understanding and more practice fostering diffusion than innovation (Norberg-Bohm, 1999).

The research questions of the study focused on are; how the top management of the GLCs perceive green; and how they transform their organisations and business ventures in order to be green?

\section{Literature Review}

Businesses are above all things, a collection of people and to be the best, the best people should be hired to create and nurture the best teamwork (Leighton, 2007). For the GLCs to sustain in the industries they are operating, they have to find ways to optimize the organisational innovation that can improve their organisations' competencies. Green innovation adoption and diffusion have been actively done across the organisations throughout the world as a means to improve the quality, supply chain and working environment. Wal Mart, DHL, Microsoft and Toyota are among the giant companies in the world that give technological change as their high priority especially in their product supply chain to cut cost and reduce delivery time to the customers (Friedman, 2006). It is green when considering fewer places for stocking when warehouses only keep things for a week. The products that are slower in sale will be replaced as soon as possible with the most saleable one. All the chains are linked with the latest ICT network where the 
headquarters can detect which colours or models are popular in which outlet sold by which persons.

Government-linked Companies or GLCs are defined as companies that have a primary commercial objective and in which the Malaysian Government has a direct controlling stake. Controlling stake refers to the Government's ability (not just percentage ownership) to appoint Board of Director members, senior management, make major decisions (e.g. contract award, strategy, restructuring and financing, acquisitions and divestments etc) for GLCs either directly or through Government-linked Investment Companies or GLICs (Berhad, 2009).

The study by Singh and Ang (1999) has found that efficiently managed GLCs, and well formulated and implemented strategies are critical for the success of business organisations. Top managers' leadership characteristics and styles could significantly impact an organisation's creativity and innovative ability. Companies which delegate more autonomy to employees are less innovative due to factors of power distance, and balance between empowerment and specificity of guidance provided by the top manager (Jung, Chow \& Wu, 2003).

It is very important for GLCs to be lead by the top managers whom leadership factors can enhance the vision of the green organisation operating in green business scenario. New leaders will continue to learn through a collection of experiences and exposure to new ideas and the flow of knowledge. While different types of innovation are common place such as breakthrough, sector and technological, most approaches will benefit from a social constructionist perspective that is linked to the establishment of various learning processes and innovative cultures (Murray \& Blackman, 2006).

GLCs practices in Malaysia may not be the same as practices by government in other countries. Even the meaning of green innovation is also bringing different perspective to different people and organisations. Therefore this exploring study in the leadership and the impact of green innovation implementation in the organisation, can contribute to the body of knowledge development in the area of innovation and technology management.

GLCs managers are usually appointed for the ranks of senior civil servants and military officers being promoted on the basis of their performance and high quality but they are also being criticized for being too risk-averse and lacking sufficient entrepreneurial drive. A number of new senior executives brought into the GLCs from the private sectors and some from abroad subsequently, also left before completing their contracts (Ramirez \& Tan, 2004).

The leadership of the top management is critical when implementing the green innovation as it would change the culture through the vision they bring. As being handpicked by the Prime Minister, the top management has to operate with restriction power in some decision making due to political will, and this could jeopardize the performance and future of the organisation directly, and the county indirectly if the top management cannot perform with the interest of the country and nation.

There is limited study on the top management leadership in the Malaysia GLCs with respect to the green innovation context. Most of the studies done are to find the leadership styles related to the GLCs performance, human resource issues, or technology management tools and practices in the organisations. The aim of this study is to promote innovation that reduces environmental impacts through waste minimization, thus moving us toward the goal of a minimal waste society (NorbergBohm, 1999), and making us understand how the top management accommodates their leadership to the surrounding. 
Under NEAC's (National Economy Advisor Committee) recommendations, eight Strategic Reform Initiatives (SRIs) will be anchored with SRI 8 that is to ensure the sustainability of growth by preserving our natural resources and safe-guarding the interest of future generations through complementing the sustainable public finances through stringent fiscal discipline (NEAC, 2010). This is where Green Technology plays a very significant contribution in terms of efficiency and investment. The leadership determined in this study will be the additional key elements for the government to consider when choosing the top managers running the GLCs that can fulfil the aspiration of making year 2010 as the Year of Innovation \& Creativity for Malaysia to fit into the New Economy Model.

In their study to develop a framework for examining leadership in extreme contexts, Hannah, Uhl-Bien, Avolio and Cavarretta (2009) notice the importance of leadership dynamic study has on the reliably successful performance in extreme events where leaders cannot jeopardize the organisations future with their wrong judgment in decision making. With respect to this study where current global economic challenges and environmental critical issues are the extreme contexts, top management of Malaysia GLCs can adopt and diffuse green innovation in their businesses strategy in order to keep their business sustained and successful. Due to the constraints and contingencies in green innovation contexts, the confirmation on the validity of assumptions and the boundaries of current models of leadership will be further granted (Hannah et al., 2009).

From this study finding, it is the intention of the researcher to introduce additional building blocks that contribute to future theory-building and research in having a better knowledge of leadership in green innovation that enlightens a significant gratitude of the mechanisms and ontology of leadership and impacts on green innovation. With highly motivation to opt for 'green' around the world, the leadership of top management is very critical in bringing the organisation to become green organisation. New business paradigms and models can only be initiated if having the appropriate leadership that senses the competitive advantage green innovation has over their business competitors.

Green Technology has created new jobs and has reduced others for example; more bills can be paid online and this will reduce the jobs of the person at the bank counter. Knowledge workers are using portable ICT tools such as; i-Phone and Blackberry to send emails, check the news, and have meeting over the line with colleagues from a different continent with a different time zone. Green Technology not only makes information travels faster but decision and action by the right authorities, such as top managers, can be taken appropriately and concurrently with the situation happening anywhere the organisation is operating.

With the increase in number of people to be served every year, the GLCs need to take more significant role in championing green innovation through their Green Technology adoption in the administrative and technical operations levels.

\section{Research Design}

In determining the research design, the researchers have to consider the philosophical worldview assumptions that they bring to the study, the strategy of inquiry that is related to this worldview and the specific methods or procedures of research that translate the approach into practice (Creswell, 2009). The interpretive and theoretical frameworks have been applied in the qualitative by researchers to shape their study. The sampling tactics used a saturated approach.

The strategies of inquiry for qualitative approach are constitutes of narrative research, phenomenology, grounded theory, ethnography and case study (Creswell, 
2009). This study uses multiple case studies together with interpretive approach. Yin (2009) stated that case studies are generalizable to theoretical propositions and not to populations or universe. Due to that reason, a different organisation might find value through supporting innovation in different ways (Tabor, 2007).

For the initial data collection, the researchers conduct an individual interview and a focus group discussion interview. A prominent statesman participates in the individual interview. The focus group discussion interview is conducted with the involvement from the top managers of the GLCs. Focus groups can be used both during the preliminary or exploratory stages of a research project, where questions are explored and hypotheses generated, and at later stages for assessing the development, effectiveness or impact of green innovation implementation (Litosseliti, 2003).
Both interviews assist the researchers to get information from the people inside the GLCs and how they deal with green innovation in their companies. Data from both collection methods were triangulated to get a better understanding of the research problems. Moran-Ellis et. al, (2006) use triangulation to refer to the epistemological claim that findings are compared from two or more different research methods that enable the researcher to conclude whether an aspect of a phenomenon has been accurately measured.

\section{Findings and Descriptions}

From the interviews conducted, eight themes have been identified to emerge from the data collection that are related to the focus of the study. The emerged themes from the data are tabulated below. 
Table 1: Themes Emerged from the Data Collection

\begin{tabular}{|c|c|}
\hline Initial & Themes \\
\hline LdQua & $\begin{array}{l}\text { - Leader's Qualities describe the characteristics also being referred to as the } \\
\text { subjective attributes that the top management should possess (either } \\
\text { already born with them or through transformation) to be competent and } \\
\text { efficient in understanding the current financial and investment market, new } \\
\text { customer demand and new regulatory }\end{array}$ \\
\hline NormP & $\begin{array}{l}\text { - Normal Practice describes the normal activities, perceptions and decision } \\
\text { making done by the top management in the organisational strategies and } \\
\text { operation that restrict the organisation to venture into new change and } \\
\text { innovation. }\end{array}$ \\
\hline DevLd & $\begin{array}{l}\text { - Developing Leaders suggests ways that the future and current top } \\
\text { management should be groomed and prepared for new business challenge } \\
\text { through gradual assessment, new skills and knowledge within and outside } \\
\text { organisation, at regional and global level }\end{array}$ \\
\hline Inno & $\begin{array}{l}\text { - Innovation refers to the needs and necessity that top management should } \\
\text { act upon for the survival, success and sustainability of their organisation. It } \\
\text { is placed at high rank in the organisational strategic planning. }\end{array}$ \\
\hline GI & $\begin{array}{l}\text { - Green Innovation is defined as an innovation that is related to green } \\
\text { products or processes, including the innovation in technologies that are } \\
\text { involved in energy-saving, pollution-prevention, waste recycling, green } \\
\text { product designs, or corporate environmental management that is identified } \\
\text { as current effective innovation to reduce operational cost, improve } \\
\text { corporate image and branding to the customer perceptions, and corporate } \\
\text { social responsibility. Administration and Operation/Production are the } \\
\text { places where technological change is directly involved and stakeholders } \\
\text { (top management, employees, customers, users, community) need to adapt } \\
\text { and learn to use the new innovation. }\end{array}$ \\
\hline Ld Role & $\begin{array}{l}\text { - Leader's Roles reflect the responsibility of the top management in running } \\
\text { the organisation - they must pay attention to details on the financial and } \\
\text { investment issues, groom talents from the inside to shoulder the future } \\
\text { organisation leadership, to be sensitive to sustainability issue (people, } \\
\text { planet, profit), and to admit and react fast to failure }\end{array}$ \\
\hline Cult & $\begin{array}{l}\text { - Culture has very much concern on the value systems of certain races to } \\
\text { success, working culture, work ethics, gender bias that top management } \\
\text { should influence through motivation and behaviours to ensure that } \\
\text { organisation can success and sustain. The young executives, Generation Y, } \\
\text { are so eager to be at the top that less exposure and experience at certain } \\
\text { corporate levels might bring disadvantage for them when they are at the } \\
\text { top. }\end{array}$ \\
\hline GLCsChl & $\begin{array}{l}\text { - GLCs' challenges show the challenges the top management leadership of } \\
\text { GLCs face that at some points are different from Multinational Companies } \\
\text { (MNC) or Small-Medium Enterprise (SME) in terms of vision, strategies and } \\
\text { directions. GLCs, as the government investment arms, need to balance } \\
\text { between strategies and political will because they are labelled as national } \\
\text { companies that carry national aspiration. }\end{array}$ \\
\hline
\end{tabular}


Leader's Qualities (LdQua) are the characteristics that are also being referred to as the subjective attributes that the top management should possess. The participants agree that the attributes can be obtained whether they are already born with them or through nurturing transformation process. Leaders in the top management positions must be competent and efficient in understanding the current financial and investment market, new customer demand, and new imposed regulatory that is related to their companies operation.

In Normal Practices (NormP), the participants have the same opinion that normal activities, perceptions and decision making done by the top management in the organisational strategies and operation have restricted the organisation to venture into new challenge, change and innovation.

For Developing Leaders (DevLd), the participants suggest approaches of how the future and current top management should be groomed and prepared for new business challenges. Potential leaders can go through gradual assessment to gain new skills and knowledge within and outside the companies, at regional and global levels.

Innovation (Inno) refers to the needs and necessity that top management should act upon for the survival, success and sustainability of their organisation. The participants concur that innovation should be placed at high rank in the organisational strategic planning.

Green Innovation $(G I)$ is defined as an innovation practice concept in the organization related to energy saving, pollution prevention, waste recycling, green product designs, or corporate environmental management. In business, it is identified as current effective innovation to reduce operational cost, improve corporate image and branding to the customer perceptions, and corporate social responsibility. Administration and Operation/Production are the places where technological change is directly involved and stakeholders (top management, employees, customers, users, community) need to adapt and learn to use the new innovation.

Leader's Roles (LdRole) reflect the responsibilities of the top management in running the organisation. As leaders, they must pay attention to details on the financial and investment issues, groom talents from the inside to shoulder the future organisation leadership, to be sensitive to sustainability issue (people, planet, profit), and to admit and react fast to failure so that appropriate corrective measures can be done before they are too late.

The participants believe Culture (Cult) is very much concerned with the value systems of certain races to success. Issues regarding working culture, work ethics, and gender bias must be handled properly by the top management through motivation and behaviours' influences to ensure that the organization can success and sustain. The young executives, especially the Generation $\mathrm{Y}$, are so eager to be in the top positions. Unfortunately, less exposure, experience, knowledge and skills at certain corporate levels might bring disadvantage for them when they are at the top. Their deficiency in certain areas and knowledge will jeopardize the companies' future.

GLCs' Challenges (GLCsChl) show the challenges the top management leadership of GLCs face at some points are different from Multinational Companies (MNC) or SmallMedium Enterprise (SME). They are different in terms of national aspiration, visions, strategies and directions. GLCs, as the government investment arms, need to balance between strategies and political will because they are labelled as national companies that carry national aspiration. As the initial findings, those identified themes guide the researchers to understand the importance of green innovation in the organizational sustainability in the context of 
GLCs. The rigorous document analysis related to the study will be done to get more information and identify more new or additional data emerging from them. The triangulation of the data is not yet done as rigorous document analysis and with the subordinates are still in the process.

If companies try to enhance their green brand equity, they should incorporate the ideas of green brand image, green satisfaction, and green trust into their longterm environmental strategies in the stage of strategy planning (Chen, 2010).

\section{Conclusion}

This study aims to understand the top management leadership in the GLCs with the current situation that focuses on environment preservation. Green innovation implementation in the administration and operation/production across the companies is targeted to reduce cost, improve corporate branding and make process more efficient.

The researchers conduct two individual interviews and one focus group discussion interview as the initial data collection to get clear understanding of the issues. Then documents published related to the green innovation in and by GLCs are being collected. The emerging themes from the data show that eight themes are identified by the top management as being crucial for the nature of leadership with regards to green innovation. Therefore, in conclusion, the top management must have all the best attributes but the success is very much depending on how their leadership attributes are tailored and changed with the current situation and future demands.

For future study, it can be expanded to understand how MNCs and SMEs in Malaysia implement green innovation in their companies. The scope of the study should also cover the other groups of executives in the companies such as executives, lower management and middle management.

\section{Acknowledgement}

The researchers would like to thank all the respondents and organisations that have participated in the data collection processes in this study. Their cooperation, support and knowledge sharing are very informative and contributed a lot in answering the study questions and in enhancing the understanding of the issues in depth.

\section{References}

Berhad, K. N. (2010). "What are GovernmentLinked Companies (GLCs)?," Retrieved January 2, $2010 \quad$ from http://www.khazanah.com.my/faq.htm\#que s8

Chen, Y.-S. (2010). "The Drivers of Green Brand Equity: Green Brand Image, Green Satisfaction, and Green Trust," Journal of Business Ethics, 93(2), 307-319.

Creswell, J. W. (2007). Qualitative Inquiry and Research Design: Choosing among Five Approaches (2nd Ed.), Thousand Oaks, CA: Sage Publications.

Friedman, T. L. (2006). The World Is Flat: The Globalized World in the Twenty-First Century (updated 1st ed.), London: Penguin Group.

Green, K., Morton, B. \& New, S. (2000). "Greening Organizations: Purchasing, Consumption, and Innovation," Organization \& Environment, 13(2), 206-225.

Hannah, S. T., Uhl-Bien, M., Avolio, B. J. \& Cavarretta, F. L. (2009). "A Framework for Examining Leadership in Extreme Contexts," The Leadership Quaterly, 20, 897-919.

Jung, D. I., Chow, C. \& Wu, A. (2003). "The Role of Transformational Leadership in Enhancing Organizational Innovation: Hypotheses and Some Preliminary Findings," The Leadership Quarterly, 14, 525544. 
Karim, F. N. (2010, April 27). 'Tax Breaks for Green Designs,' New Straits Times, p. 4.

Leighton, A. (2007). 'On Leadership: Practical Wisdom From the People Who Know,' London: Random House Business Books.

Litosseliti, L. (2003). "Using Focus Groups in Research," London: Continuum.

Moran-Ellis, J., Alexander, V. D., Cronin, A., Dickinson, M., Fielding, J., Sleney, J. \& Thomas, H. (2006). "Triangulation and Integration: Processes, Claims and Implications," Qualitative Research, 6(1), 4559.

Murray, P. \& Blackman, D. (2006). "Managing Innovation through Social Architecture, Learning, and Competencies: A New Conceptual Approach," Knowledge and Process Management, 13(3), 132-143.

NEAC. (2010). 'Why Do We Need the NEM and What Are Its Goals?,' Part 1 - New Economic Model for Malaysia - Strategic Policy Directions - Full Report, Retrieved July 19, 2010 from

http://www.neac.gov.my/sites/default/files /Chapter\%201\%20\%20Why\%20do\%20we $\% 20$ need $\% 20$ the $\% 20$ NEM $\% 20$ and $\% 20$ what $\% 20$ are\%20its\%20goals_0.pdf.

Norberg-Bohm, V. (1999). "Stimulating 'Green' Technological Innovation: An Analysis of Alternative Policy Mechanisms," Policy Sciences, 23, 13-38.

PETRONAS (2010). "Petronas Participates in Earth Hour 2010. Media Releases," Retrieved March 26, 2010, from http://www.petronas.com.my/media_centre /press_releases_details.aspx?Title $=113$

Ramirez, C. D. \& Tan, L. H. (2004). "Singapore Inc. versus the Private Sector: Are Government-Linked Companies Different?," IMF Staff Papers, 5(3), 510-528.

Singh, K. \& Ang, S. H. (1999). 'Government in Business: An Empirical Analysis of the
Strategies and Success of Government Linked Corporations in Singapore,' Academy of Management Proceedings, 1-6.

Tabor, J. H. (2007). 'Leadership, Culture, and Organizational Innovation: The Case of Commerce Bank,' Unpublished Ph.D Dissertation. School of Professional Studies, Gonzaga University, USA.

Yin, R. K. (2009). Case Study Research: Design and Methods (5th ed. Vol. 5), Thousand Oaks, CA: Sage Publications. 